\title{
SISTEM INFORMASI DAN PENGOLAHAN DATA KRIMINAL DI POLRES PASAMAN BARAT DENGAN AKSES VIRTUAL HOST BEBASIS CLIENT SERVER MENGGUNAKAN BAHASA PEMROGRAMAN PHP DAN DATABASE MYSQL
}

\author{
Larissa Navia Rani ${ }^{1}$, Hari Marfalino ${ }^{2}$,Putri Asysyura Yuska ${ }^{3}$ \\ Universitas Putra Indonesia "YPTK"Padang, Jl.Lubuk Begalung, Padang - Sumbar \\ larissa_navia_rani@upiyptk.ac.id ${ }^{1}$, hari_marfalino@upiyptk.ac.id ${ }^{2}$ \\ , asysyuraputri@gmail.com ${ }^{3}$
}

\begin{abstract}
Abstrak- The rapid development of computer technology and information greatly helps work in storing, accessing to data processing becomes faster and easier, this has triggered various fields in utilizing this with the use of computer-based information systems, especially for intelligence units in western security police. The system that will be created uses access to the virtual host-based client server. Modeling used UML modeling, this system is built using PHP programming language and MYSQL database. The results of the study show that the information system designed can process criminal data and is able to be implemented at the research site..
\end{abstract}

Keywords -data processing information systems, criminal acts, client servers.

Intisari -Pesatnya perkembangan teknologi komputer dan informasi sangat membantu pekerjaan dalam melakukan penyimpanan, pengaksesan sampai pengolahan data menjadi lebih cepat dan mudah hal ini memicu berbagai bidang dalam memanfaatan hal tersebut dengan penggunaan sistem informasi berbasis komputer khususnya bagi satuan intelkam di polres pasaman barat. Sistem yang akan dibuat menggunakan akses virtual host berbasis clien server. Pemodelan yang di gunakan menggunakan pemodelan UML, sistem ini di bangun menggunakan bahasa pemograman PHP dan database MYSQL. Hasil penelitian menunjukan bahwa sistem informasi yang di rancang dapat mengolah data kriminal dan mampu di implementasikan di tempat penelitian.

Kata Kunci-sistem informasi pengolahan data, tindak pidana, clien server

\section{PENDAHULUAN}

Teknologi informasi pada saat ini sangat membantu pekerjaan dalam melakukan penyimpanan, pengaksesan sampai pengolahan data menjadi lebih cepat dan mudah. Hampir semua bidang sudah beralih pada penggunaan teknologi salah satu penerapannya adalah sistem informasi (Kennedy,2015).

Polres Pasaman Barat merupakan satuan organisasi Polri yang berkedudukan dikabupaten Pasaman Barat yang bertujuan untuk mewujudkan keamanan yang meliputi terpeliharanya keamanan dan ketertiban masyarakat, tertib dan tegaknya hukum,terselenggaranya perlindungan,pengayoman, dan pelayanan masyarakat yang menjunjung tinggi hak asasi manusia sebagai terlihat pada rumusan Pasal Undang-undang No 2 Tahun 2002 tentang Kepolisian (Burhanuddin,2016)

Proses pengolahan data pada Intelkam Polres Pasaman Barat masih di lakukan dengan microsoft word yang mengurangi efesiensi kerja dan mempersulit anggota kepolisian melakukan penanganan dalam pengolahan data kriminal. Hal ini mengalami kelemahan dalam pengolahan data yang tidak efektif dan efisien keterlambatan dalam pencarian data, bahkan data yang ada dapat mengalami kerusakan bahkan hilang (Serli,2017).

\section{TINJAUAN PUSTAKA}

\subsection{Pengertian Sistem}

Definisi system secara umum adalah sekumpulan objek-objek yang saling berelasi dan berinteraksi serta hubungan antar objek bias dilihat sebagai satu kesatuan yang diranjang untuk mencapai satu tujuan. Dengan demikian, secara sederhana system dapat diartikan sebagai suatu kumpulan atau himpunan dari unsur atau himpunan dari unsur atau variable-variable yang saling terorganisasi (Rani, 2014).

\subsubsection{Karakteristik Sistem}

Suatu sistem yang baik harus mempunyai tujuan dan sasaran yang tetap karena hal ini akan sangat menentukan dalam medefenisikan masukan yang dibutuhkan sistem dan juga keluaran yang 
dihasilkan. Suatu sistem mempunyai karakteristik atau sifat-sifat dan komponen-komponen tertentu, yaitu (Handayani, 2016) :

1. Komponen Sistem

Suatu sistem terdiri dari sejumlah komponen-komponen yang saling berinteraksi, artinya saling bekerja sama membentuk suatu kesatuan.

2. Batasan Sistem

Ruang lingkup sistem merupakan daerah yang membatasi antara sistem dengan Sistem yang lain atau sistem dengan lingkungan luarnya.

3. Lingkungan luar sistem

Bentuk apapun yang ada diluar ruang lingkup atau batasan sistem yang mempengaruhi operasi sistem tersebut disebut lingkungan luar sistem.

4. Penghubung Sistem

Media yang menghubung sistem dengan subsistem lain disebut penghubung sistem atau interface.

5. Masukkan Sistem

Energi yang dimasukkan kedalam kedalam sistem disebut masukan sistem, yang dapat berupa pemeliharaan dan sinyal.

6. Keluaran Sistem

Hasil energi yang diolah dan diklasifikasikan menjadi keluaran yang berguna. Keluaran ini merupakan masukan bagi subsistem yang lain seperti sistem informasi.

7. Pengolahan Sistem

Suatu sistem dapat mempunyai suatu proses yang akan mengubah masukan menjadi keluaran, contohnya adalah sistem akuntansi.

8. Sasaran Sistem

Suatu sistem memiliki tujuan dan sasaran yang pasti dan bersifat deterministik.Kalau suatu sistem tidak memiliki sasaran, maka operasi sistem tidak ada gunanya.

\subsection{Pengertian Pengolahan Data}

Menurut Budi Sutejo (2006), pengolahan data merupakan tahap dimana data diolah sesuai dengan prosedur yang telah dimasukkan sedangkan, dan MenurutSutabri (2005),pengolahan data adalah suatu proses menerima data sebagai masukan (input) memproses (procesing) menggunakan proses tertentu, dan mengeluarkan hasil proses data tersebut dalam bentuk informasi (output) (Mahyuni, dkk, 2014).

\subsection{Client server}

Menurut Andi (2010) Client - Server adalah salah satu model komunikasi dua computer atau lebih yang berfungsi melakukan pembagian tugas.Client berfungsi untuk melakukan input, update, penghapusan dan menampilkan data sebuah database. Sementara server bertugas menyediakan pelayanan untuk melakukan manajemen, yaitu penyimpanan dan pengolahan database (Handayani ,2016).

\section{ANALISA SISTEM}

3.1. Evaluasi Sistem Yang Sedang Berjalan

Analisa sistem adalah penguraian dari suatu sistem informasi yang utuh kedalam bagian komponenkomponennya dengan maksud untuk mendefenisikan danmengevaluasi permasalahanpermasalahan,kesempatan-kesempatan, hambatanhambatan yang terjadi dan kebutuhan-kebutuhan yang diharapkan sehingga dapat diusulkan perbaikannya.

\subsection{Analisa Input dan Output}

\subsubsection{Analisa Input}

Sebelum dirancang dan diimplementasikannya sistem data kriminalitas pada Kepolisian Negara Republik Indonesia Polres Pasaman Barat, Mengidentifikasi masalah merupakan langkah dimana kita menganalisa masalah - masalah yang ada, baik itu kemungkinan adanya ketidakberesan di dalam sistem yang lama maupun semakin meningkatnya kebutuhan informasi.

\subsubsection{Analisa Output}

Analisa output adalah analisa yang dilakukan terhadap output- output yang ada pada Kepolisian Negara Indonesia Polres Pasaman Barat. Adapun laporan Output dari kepolisian Negara Indonesia Polres Pasaman Barat yaitu laporan daftar personil Sat Intelkam.

\subsection{Perancangan Sistem dengan Unified Modeling Languange (UML)}

Unified Modelling Langguge (UML) adalah standarisasi internasional unuk notsi dalam bentuk grafik, yang menjelaskan tentang analisis dan desain perangkat lunak yang dikembangkan dengan pemoraman beriontasi objek.UML menawarkan sebuah standar untuk merancang model sebuah sistem. Adapun UML yang dirancang dalam pembuatan sistem ini sebagai berikut:

\subsubsection{Usecase Diagram}

Use case Diagram, menggambarkan sekelompok Use case dan aktor yang disertai dengan hubungan diantaranya. Diagram Use cases ini menjelaskan dan menerangkan kebutuhan atau requirement yang diinginkan user, serta sangat berguna dalam menentukan struktur organisasi dan model dari pada sebuah sistem. 


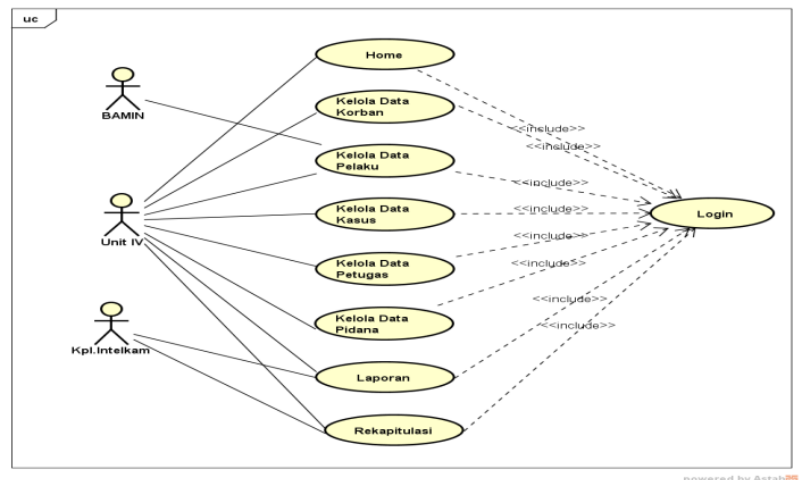

Gambar 3.1 Use Case Diagram

\subsubsection{Class Diagram}

Class diagram menampilkan eksistensi atau keberadaan dari class-class dan hubungan (relationship) dalam desain logikal dari sebuah sistem.

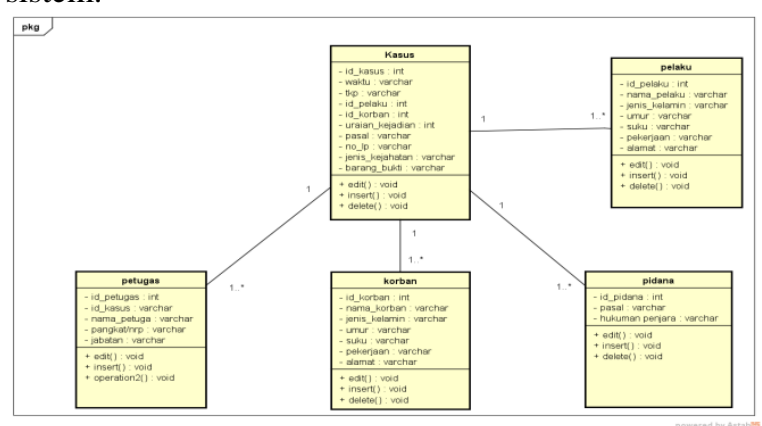

\subsubsection{Aktivity Diagram}

Gambar 3.2 Class Diagram

Diagram ini menjelaskan segala aktivitas yang bisa dilakukan oleh dengan memilih menumenu yang tersedia pada sistem.

\subsubsection{Sequence diagram}

Sequence diagram digunakan untuk menggambarkan perilaku pada sebuah scenario secara detail menurut waktu.

\subsubsection{Deployment Diagram}

Diagram Deployment menggambarkan tata letak sebuah sistem secara fisik, dengan menampakkan bagian-bagian software yang berjalan pada bagianbagian hardware.

\section{TESTING dan IMPLEMENTASI \\ 4.1. Implementas \\ i Sistem}

Implementasi sistem merupakan tahap meletakan sistem supaya siap untuk dioperasikan.Didalam implementasi sistem ada beberapa tahap yang harus dilakukan diantaranya adalah menerapkan rencana implementasi, melakukan kegiatan implementasi dan tindak lanjut implementasi. Untuk mengimplementasikan program aplikasi yang telah dirancang, maka diperluan sebuah alat bantu berupa komputer, yang mana untuk mengoperasikan komputer itu sendiri yang memerlukan tiga buah komponen pendukung seperti hardware, software, dan brainware.

\subsubsection{Halaman Login}

Form Login merupakan form untuk masuk sebagai admin dan user, dimana user dan admin masuk sesuai dengan kapasitasnya masing-masing lebih jelas dapat dilihat pada Gambar 4.17 berikut :

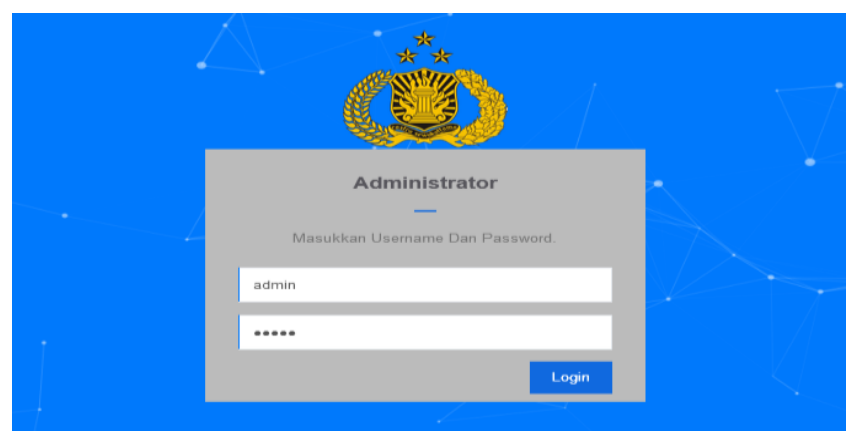

Gambar 4.17 Halaman Login User

\subsection{Halaman Input Data}

Halaman ini berisikan data-data yang di input kan oleh admin dan form - form penginputan data.

\subsubsection{Form Entri Data Korban}

Form Entri data korban merupakan form untuk mengisi data-data korban kasus kriminal. Bentuk form kelola data korban seperti pada Gambar 4.19:
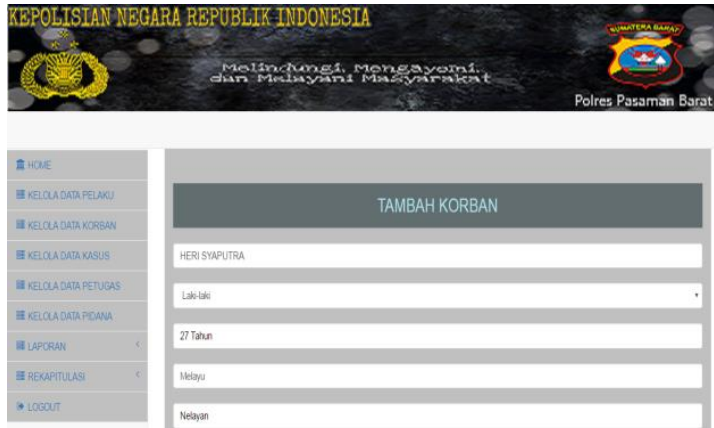

Gambar 4.1 Form Entri Data Korban

\subsubsection{Form Entri Data Pelaku}

Form Entri data pelaku merupakan form untuk mengisi data-data pelaku. Bentuk form kelola data pelaku seperti pada Gambar 4.21 :
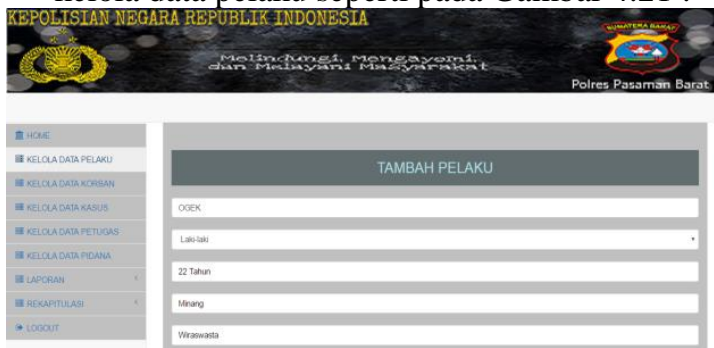

Gambar 4.2 Form Entri Data Pelaku

\subsubsection{Form Entri Data Kasus}

Form Entri data kasus merupakan form untuk mengisi data-data kasus kriminal. Bentuk 
form entri data kasus seperti pada Gambar 4.23
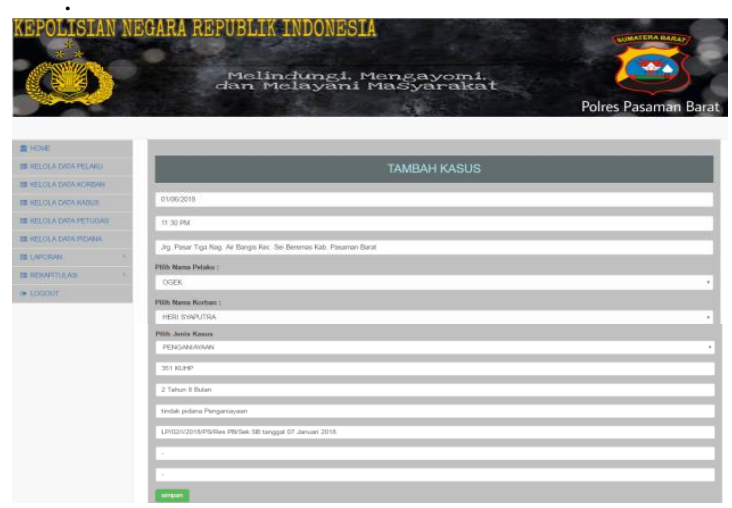

Gambar 4.3 Form Entri Data Kasus

\subsubsection{Form Entri Data Petugas}

Form Entri data kasus merupakan form untuk mengisi data-data petugas. Bentuk form kelola data petugas seperti pada Gambar 4.25 :

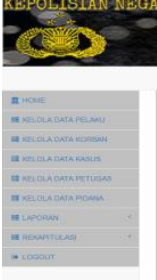

$2 \rightarrow$

Gambar 4.4 Form Entri Data Petugas

\subsection{Form Entri Data Pidana}

Form Entri data pidana merupakan form untuk mengisi data-data pidana pada kasus kriminal. Bentuk form entri data pidana seperti pada Gambar 4.27 :

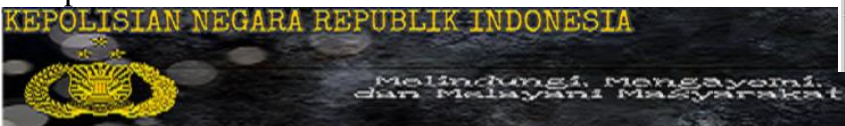

4.2.7 Tampilan Halaman Laporan dan Rekapitulasi Pada Kepala Intelkam

Tampilan data merupakan form yang berisi tentang laporan dan rekapitulasi. Adapun tampilan laporan dan rekapitulasi dapat dilihat pada gambar 4.29 berikut ini :

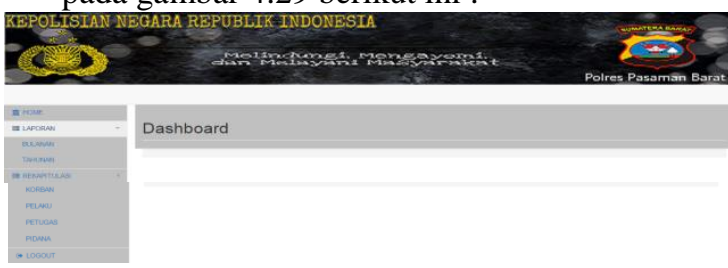

Gambar 4.7 Halaman Kelola Data pidana

\subsubsection{Laporan Data Kasus Perbulan}

Laporan Data Kasus merupakan form yang berisi tentang laporan data kasus bulanan perjenis kasus kriminal. Adapun form data laporan data kasus dapat dilihat pada gambar 4.30 berikut ini:

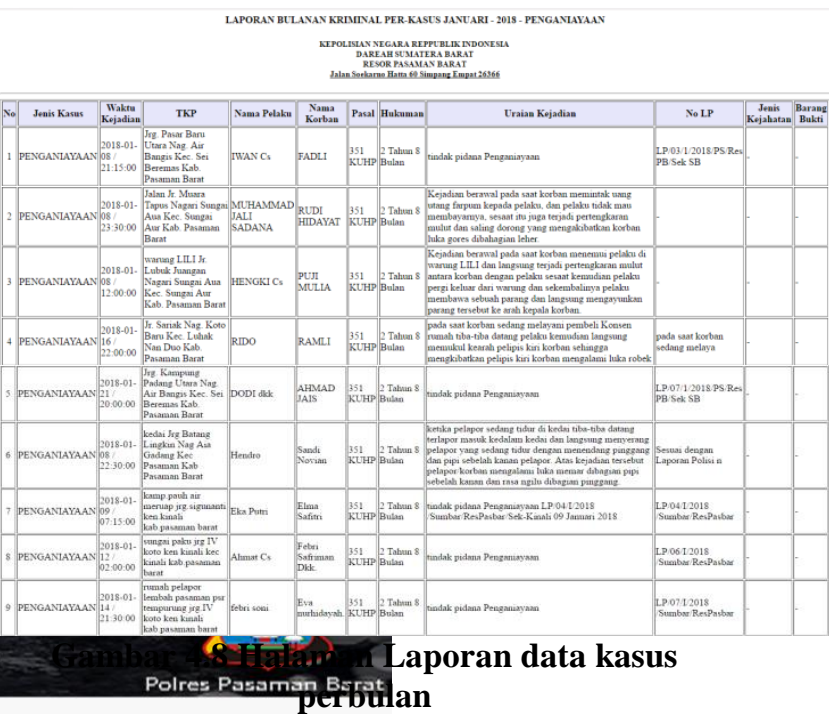

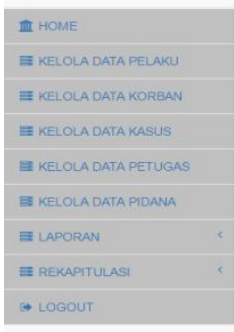

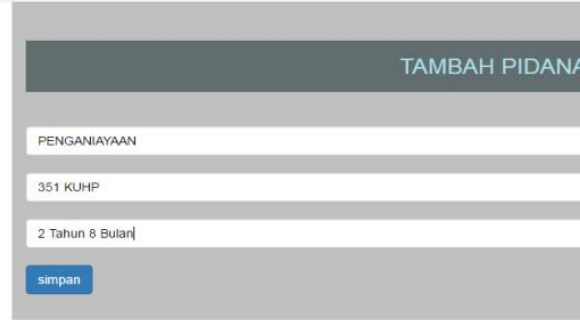

Gambar 4.5 Form Entri data kasus

\section{BAMIN}

\subsubsection{Tampilan Halaman Data Pelaku Pada}

Tampilan data pelaku merupakan data yang berisi tentang data pelaku kriminal. Adapun form data pelaku dapat dilihat pada gambar 4.28 berikut ini :

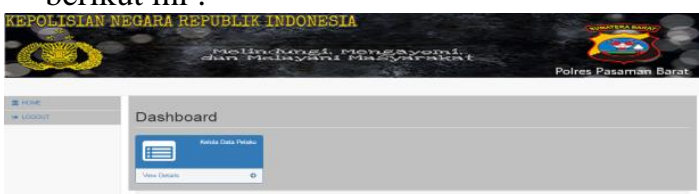

Gambar 4.6 Halaman Tampilan Data Pelaku

\section{KESIMPULAN}

Dari hasil analisa, perancangan, pengujian, dan implementasi program yang telah dilakukan terhadapsistem informasi dan pengolahan data kriminal di polres pasaman barat, maka dapat ditarik beberapa kesimpulan yang berkenaan dengan system pengolahan data dengan penerapan bahasa pemrograman PHP yaitu:

1. Dengan diterapkan sistem baru ini dapat membantu pihak intelkam dalam pengolahan data criminal dan mengurangi kesalahankesalahan dalam melakukan pencatatan data kriminal.

2. Tujuan perancangan sistem ini untuk membantu pihak intelkam memberikan informasi saat dibutuhkan dan tidak membutuhkan waktu yang lama dalam pencarian data.

3. Dengan penggunaan sistem komputerisasi yang optimal, maka dapat mengurangi kesalahan 
dalam pencatatan data laporan kriminal dan meminimalkan kesalahan-kesalahan yang terjadi dalam mempercepat proses cetak laporan.

\section{SARAN}

Dengan adanya uraian terhadap sistem yang sedang berjalan maupun terhadap sistem yang dikembangkan maka penulis memberikan saransaran yakni:

1. Penerapan sistem informasi yang berbasiskan bahasa pemrograman PHP dan Mysql sebaiknya segera diterapkan untuk meningkatkan kinerja serta menghasilkan informasi yang lebih akurat.

2. Spesifikasi dari perangkat komputer yang akan digunakan oleh sistem yang baru sebaiknya disesuaikan dengan kebutuhan standar program aplikasi yang akan dijalankan.

3. Agar sistem yang dirancang dapat bekerja secara efektif dan efisien, maka diperlukan tenaga terampil dalam pengoperasian aplikasi yang dibuat.

4. Dalam rancangan sistem yang baru ini, diharapkan pihak polisi Polres Pasaman Barat dapat mengevaluasi sistem informasi pengolahan data dan memberikan masukanmasukan jika ditemukan kekeurangankekeurangan agar sistem yang baru dirancang ini diperbaiki kembali agar lebih sempurna dari sebelumnya.

\section{DAFTAR PUSTAKA}

[1] Handayani, Reti. 2016. "Sistem Informasi Hasil Belajar Siswa Smk Elektronika Indonesia Bukit Tingi Berbasis Client Server". ISSN : 2355-7958.

[2] H.Burhanuddin. 2014. "Efektifitas Pelaksanaan Patroli Terpadu Dalam Upaya Menekan Tingkat Kriminalitas (Pada Polres Bungo)”. ISSN : 1693-0819.

[3] Kennedy, janero. 2015. "Aplikasi system informasi pengolahan data pada rektorat reserse criminal khusus polda sumbar". ISSN : 2302-3805.

[4] Rani, Larissa Navia. 2017. "Perancangan Aplikasi Sistem Informasi Sebagai Median Promosi Menggunakan Bahasa Pemograman PHP dan Database MySql Pada Kinali Auto Rental''ISSN : 2356-0010.

[5] Serli. 2017. "Perancangan Aplikasi Pengolahan Data Akademik Berbasis Client Server Pada SMA NEGERI 1 Walenrang”.'ISSN : 2580-7960.

[6] Mahyuni.sharipuddin. Martono. 2014. "Perancangan system pengolahan data sma negeri 6 kabupaten tebo". ISSN : $1978-8126$ 